\title{
COMPREHENDING THE COMPLEXITY OF A COUNTRY
}

\author{
Hans Kuijper \\ Independent researcher
}

\begin{abstract}
A country is a demarcated piece of land and its organized people. Differently put, a country is a tripartite system consisting of three basic, interrelated elements: its territory, its people and the organization of its people. Countries can thus be represented (modeled) by a triangle, the sides of which are variable in length. Since each and every country has a history, the triangle has to be changed into a tetrahedron. This article intends to elaborate on these abstract concepts. The subject is of utmost importance because foreign policy is the policy related to a foreign country. If a minister of foreign affairs pursues the wrong policy towards a certain country because he is ill-advised, the consequences may be disastrous.
\end{abstract}

Keywords: country study, complexity, systems science.

\section{Introduction}

Graduated in Sinology from Leiden University (NL), I could not be satisfied with the disjointed and unruly field of study I had been educated in. Sinologists have a thing to be explained (explanandum), China, but they do not have a tested or testable theory (explanans) of their own. All they can do is to pick and choose ideas by trespassing on disciplinary domains and to show off other people's feathers. Like other so-called country experts, sinologists have the bad habit of 'borrowing' a theory from one of the social or human sciences to do the explaining they miserably fail to do themselves. In doing so, they make a big mistake. For example, without being schooled in economics, sinologists are inclined to resort indiscriminately to an economic theory - not only to explain the economic development of China, but to explain the state of affairs in China tout court. Worse still, they often use a heady brew of theories advanced in the social and human sciences to picture and supposedly explain the situation in China, that is to say, theories which they are not well-schooled in and which are not or not sufficiently tested in the country. Their language skill often serves as a screen concealing this shameful behavior from a critical look. Having investigated the research done by other 'country experts', I found them fraught with the same problem.

Self-styled country experts are not the only culprits of such behavior. They can also be found among scientists such as economists, political scientists, sociologists, psychologists, legal experts, linguists, literary scientists, geographers, demographers, statisticians and ecologists who leave their home turf and feel called to let the world know about their 'expertise' in regard to a country on which they never tested their own or borrowed theories.

The challenge I had to face was whether I could come up with a solution for the fundamental problem I signaled and help 'country experts' out of the predicament they

Journal of Globalization Studies, Vol. 12 No. 2, November 2021 47-68

DOI: $10.30884 / j o g s / 2021.02 .03$ 
rarely acknowledge being in, for it is easy to be critical of current studies, but far more difficult to improve on them. It became clear to me that the following distinctions had to be made in advance in order to meet the challenge:

1) A country is an area, but an area is not necessarily a country. For example, bordered by Turkey to the north, Iran to the east, Kuwait to the southeast, Saudi Arabia to the south, Jordan to the southwest and Syria to the west, Iraq is a country in the turbulent area called the Middle East. So the criticism I level against 'Iraq experts' should be a fortiori aimed at so-called Middle East experts. The Middle East (an area) includes Iran, Turkey, Saudi Arabia and Egypt, countries (areas) that are in many ways very different. Allowing somebody to introduce a speaker or writer as a 'Middle East expert' is therefore outrageous. And yet, the renowned Brookings Institution, in Washington DC, counts dozens of 'Middle East experts'.

2) I take 'country' to be the same as 'state' or 'nation', though the two shall not be mixed up.

The state is a form of a human association distinguished from other social groups by its purpose: the establishment of a political order. Few establishers of a political order know what 'order' actually means, but to achieve their objective, they proclaim and enforce laws, which only apply to people belonging to a certain territory. The court that represents the state embodies the highest power in a country; it has no jurisdiction beyond the boundaries of the state's territory. The word state can be used descriptively (in a non-evaluative way) or prescriptively (in a normative manner). Used descriptively, 'state' stands for the politic body or political community, which has existed throughout history in a variety of different forms. Only the nomadic community is excluded from being called a state, though some form of government is intrinsic to human society. ${ }^{2}$ The descriptive definition of a state points to another characteristic. In so far as the state is concerned with a specific end, it raises the question of the rightness of this end and the means or methods employed to achieve it. Seen from this angle, the state is a perennial problem. For the state involves not only the establishment of order; the order should also be the right one. Plato, Aristotle, Augustine, Maimonides, Thomas Aquinas, Niccolò Machiavelli, Jean Bodin, Hugo Grotius, Thomas Hobbes, René Descartes, Benedict Spinoza, John Locke, Montesquieu, David Hume, Rousseau, Immanuel Kant, Adam Smith, Edmund Burke, Thomas Paine, Hegel, John Stuart Mill, Karl Marx, Friedrich Nietzsche, Leo Strauss, Michael Oakeshott, Hannah Arendt, John Rawls, Jürgen Habermas and Robert Nozick occupied themselves with the question as to what the state had to be, that is, with the concept of state in a normative way. They had different views about order, the axis of all political thinking. Political scientists, legal scientists, economists, sociologists, psychologists, anthropologists, demographers and geographers have greatly contributed to the deepening of political philosophy, which is a proof that scientific disciplines are inextricably interconnected. The approach may be different, the fundamental problem is the same: how to rule a country?

The nation-state (shortly: nation) is a combination of two elements: the politicalterritorial and the historical-cultural element. 'State' refers to the modern state, which reached fruition after the Renaissance and Reformation. The state is as a set of institutions that may be centralized or decentralized, but possesses the monopoly of violence and taxation in a demarcated and recognized territory. 'Nation' refers to a human community with a common ancestry, historical memory, living culture, and sense of belonging together. State and nation have a strained relationship. The more pronounced the 
civic-territorial elements, the less difficult has it been to bring about a fusion of state and nation; conversely, the more prominent the ethnic-cultural elements, the less probable is it that harmony between the two will be reached. Tribalism, which (like nationalism) both constrains and enables, is everywhere manifest. It is very much alive, not only in Iraq and Libya (or elsewhere in the Middle East, Asia, or Africa) but also in Australia, Canada, and the USA. Broadly defined, tribalism can be recognized in party-loyalty, ingroup bias, groupthink and the amity-enmity complex, virulent forms that have been omnipresent. Most nation-states are poly-ethnic. Some countries have an ethnic group which distinguishes itself from, and regards itself superior to, minorities, which may be politically active and unwilling to accept the culture and ascendancy of the dominant ethnic group. The Han Chinese, who vastly outnumber the Tibetans and Uyghurs and ruthlessly suppress their culture, are a case in point. Economically more advanced countries like Belgium, Canada, France, Spain and Britain also suffer from deep internal ethnic cleavages, and oppositions of the Walloons, Quebeckers, Bretons, Catalans and Scots respectively reveal the error of assuming a nation-state where there is none. Is the 'United Kingdom' a nation-state? The Englishmen, the Scots, the Welsh and the Irish will answer this question differently, reaching for their gun to strengthen their point of view. Only in a loose sense, countries like Belgium, Canada, France, Spain and Britain can be conceived of as nation-states, since they enjoyed that status internationally before ethnic nationalism (not to be confused with civic nationalism) spread to their ethnic communities.

3) Ethnologists and anthropologists are concerned with ethnic groups ('ethnies'), but certainly not with a country. Ethnology is a branch of anthropology that analyzes and compares the characteristics of different peoples. Ethnicity is often used synonymously with the term nation; it is related to the concept of race. Anthropology is the scientific study of human beings, their behavior and the societies in which they are living or have lived. Social anthropologists are concerned with patterns of behavior and cultural anthropologists with cultural meaning. ${ }^{3}$ Linguistic anthropologists study how language influences social life and biological or physical anthropologists the biological development of humans. Philosophical anthropology is a branch of philosophy delving into the essence of man, an issue which Indian and Chinese philosophers have been particularly interested in and a subject of which actions (see below) are only one, albeit a very important, aspect.

\section{A Country is a System}

Let me explain what I mean by saying that a country is a system consisting of three basic, interrelated elements.

- When we discuss the affairs or development of a country, its territory is the first that we think of. We search on a map where the country lies and how vast its territory is. Perhaps without realizing it, we are a bit of a geographer, for the core business of the geographer is studying the surface of (a part of) the Earth, that is to say, the spatial distribution of its physical and human characteristics. ${ }^{4}$ The modern geographer, who is by definition concerned with a geographic system, works in close cooperation with, or acknowledges having drawn on the work of, geologists, biologists, demographers, ecologist and social and human scientists, who are also basically systems thinkers, because they are searching for coherence. He/she is aware of the benefits of interdisciplinary (as distinct from multidisciplinary) research, knowing that truly scientific collaborating 
means $1+1>2$. The modern geographer works together without being afraid of losing his scientific identity.

Geography is not the sheer inventory of things on the surface of (a part of) the Earth. The geographic viewpoint rests upon fundamental, interrelated concepts. For example, 'location' refers to the spatial variation of physical or human phenomena. To locate, however, is to relate. Knowing the location of things or people, one knows where to find them, their coordinates, so to speak. Geographical insight comes only with knowledge of the place itself (the site) and its relations with other places (the situation). Site is the internal and situation the external aspect of a place. What is 'internal' and what is 'external' depend on how the place is defined, for example, house, city and country. The relation between places (spatial interaction) implies mobility of things, ideas, or people. Interaction requires the overcoming of distance through communication or transportation. 'Accessibility' refers to the degree to which a place can be approached from other places. The purpose of geography is to understand the character of places, that is to say, both their internal and external characteristics.

Territory is not pure extensiveness, the concatenation or juxtaposition of homogeneous elements, like the points in a plane. The territory of country A is different from the territory of country B. 'This here' and 'that there' refer to different things in the same space, for example, to the car here and the tree there, to the house here and the river there, to the street of my hometown and the mountain far away, or to the person named $\mathrm{X}$ and the person named $\mathrm{Y}$. The territory of a country is a specifically organized space having a meaning. Landscape is mindscape. Whereas the historian is primarily interested in the 'when' (the time), the first inquiry of a geographer is about the 'where' (the location); the former focuses on the sequential, the latter on the simultaneous order or ordering. ${ }^{5}$ Further down I will explain how pattern and process are intimately interrelated.

- The second basic element of the system called country is the people who belong and are emotionally attached to its territory, ${ }^{6}$ in other words, the inhabitants of the country. Looking only at their number, we enter the demographic domain. Demography is the statistical study of human populations. It encompasses the study not only of their size and composition but also of their dynamics, their changes in response to birth, migration and death. Over the last few decades, demographic models and methods have been rapidly developing and there has been an explosive growth in the range of applications of population analysis. ${ }^{7}$ Though demography is at the crossroads of disciplines such as geography, biology, ecology, sociology, psychology, economics, politics, law, anthropology and epidemiology, it offers the tools to approach a wide range of population issues. Acknowledging that both the determinants and the effects of demographics are to be ultimately explained by other disciplines, demographers have a clear and distinct analytical point of view, a unique disciplinary matrix, a scientifically distinctive sound.

- Organization is the third defining and arguably most difficult element of a country. A territory with only a number of people living on it does not make a country yet. They have to be organized, which is more than considering them to be an aggregate or putting them together. Organization is the creation of relationships for achieving a particular purpose. ${ }^{8}$ The organization of the people of a country can be viewed politically, economically and socially:

1) The political organization or order is the concern of political scientists, who divide their work into seven specialisms: the study of national governments, comparative politics, political theory (aka political philosophy), public administration, policy analy- 
sis, public law and international relations (IR). The literature on these branches (and sub-branches) is very extensive.

A political order cannot do without rules and regulations. If the inhabitants of a country do not abide by the law, chaos will result. The formulation, declaration and implementation of rules are some of the subjects legal experts are concerned with. Generally speaking, the legal domain covers the fields of public law (overlap with part of political science), property law, contract law, tort law and criminal law, each area being covered by a scholarly literature the extent of which is difficult to oversee. Public law, for example, governs the relationships between legal persons and a government, between different institutions within a state, between different branches of governments, and the relationships between persons that are of direct concern to society. Public law comprises constitutional law, administrative law, tax law, certain parts of criminal law, as well as all procedural law, extended fields of study in their own right. Laws concerning relationships between individuals belong to private law. ${ }^{9}$ Legal experts are not, at least not primarily interested in laws of nature, the concern of natural scientists. Laws of nature are to be distinguished from natural laws, the concern of philosophers of law. Legal theory is related to politics, economics, sociology, anthropology and psychology.

The demarcation of its territory implies that a country is vigilant in protecting its borders. Any infringement or encroachment will be internationally prosecuted, if necessary militarily punished. The military dimension of a country shall not be overlooked or underestimated, because it dovetails with its political, economic, legal, geographic, demographic and psychological affairs. In my view, IR-students, who focus their mind on the relations between countries rather than on the countries themselves (the relata), should pay more attention to a country's internal affairs, which affect, and are affected by, its external affairs. ${ }^{10}$ World-systems theory emphasizes the world-system as the primary unit of social analysis; de-emphasizing its geographic, demographic, political, legal, military, economic, financial, religious and cultural aspects, the theory ignores the uniqueness of individual countries by which the world-system is essentially characterized.

2) The economic organization or order concerns the framework within which economic problems related to allocation of goods and distribution of incomes are addressed. The importance of a country's economy cannot be overestimated, because it is closely connected with financial, political, legal, military, social, psychological, demographic, ecological and geographic issues. Without taking the gifts of 'Mother Earth' into account no economic activity related to food, clothing, housing, transportation, tools or machines is conceivable. Ecological economics (aka bioeconomics) studies the interplay between, and coevolution of, economic and ecological systems. Nicholas GeorgescuRoegen (1906-1994), student and protégé of Joseph Schumpeter, is considered its intellectual progenitor. In his masterpiece, The Entropy Law and the Economic Process (1971), he argues that all natural resources are irreversibly degraded when put to use in economic activity. He saw the relevance of thermodynamics (see Turns 2006; Gyftopoulos and Beretta 2012) to economics and stood at the cradle of econophysics, a thriving field of research attempting to apply physical theories and methods to economic problems. Georgescu-Roegen's book should be read in conjunction with Vaclav Smil, Energy and Civilization: A History (2017). The International Society for Ecological Economics is dedicated to advancing the understanding of the relationships between ecological, social, and economic systems. The three nested systems of sustainability are the economy, which is contained by the society, which in turn is contained by the biophysical environment. 
Georgescu-Roegen was a visionary whose thoughts were deeply rooted in those of Alfred North Whitehead (1861-1947). He died lonely at the age of 88, but his message is carried on by Herman Daly, Joshua Farley, Joan Martínez-Alier and Roldan Muradian.

3) The social organization or order of a country's population encompasses its political and economic organization. Sociology is a broad and widely ramified discipline, particularly when combined with psychology (see van Lange et al. 2012; Delamater et al. 2015; or Aronson et al. 2019). The scientific activities of the International Sociological Association (ISA) are decentralized in many interrelated research committees, each dealing with a specialty in sociology. The research committee Economy and Society is only one of them. Social scientists are rubbing shoulders with human scientists, because social activities cannot be well explained without taking the human mind (culture) into account. In fact, the bridge between social and human sciences is heavily trafficked - in both directions (see Smelser and Baltes 2015). 'No man is an island entire of itself; every man is a piece of the continent, a part of the main,' John Donne (1572-1631) aptly said. The main branches of social sciences are: anthropology, business science, cognitive science, demography, economics, geography, law, linguistics, political science, psychology, sustainability science and of course sociology. Each of them branched off into two or more than two sub-disciplines. The International Social Science Council (ISSC), founded in 1952, under the auspices of UNESCO, was an organization promoting the social sciences. ISA was just one member of the ISSC, another one being the International Political Science Association (IPSA). In July 2018, the ISSC merged with the International Council for Science (ICSU) to form the International Science Council (ISC), which is headquartered in Paris. As the scientific merging process continues, individual organizations are placed onto entirely new paths. The 'tree of knowledge,' symbol of the unification of science, is growing, while its roots deepen.

People are no robots. They have a mind (at least some of them). This is an important thing to realize, for the actions of people differ fundamentally from the events observable in nature (often by means of sophisticated equipment only). Actions like clapping, writing (a novel), smoking (a cigarette), throwing, stealing, buying and killing are not the same as events such as sneezing, snoring, stumbling, falling, delivering (a baby), raining and dying. Events are caused. With actions, however, interests, motives, beliefs or reasons are involved; actions are based on internal or external experiences and inherently related to attitudes (ways of behaving). Actions can be a custom or habit (something that is done regularly) or take into account the actions and reactions of more than one individual (agent), in which case we speak of (symbolic) interactions or social actions (involving communication). These are all subjects in which not only social and human scientists but also philosophers and authors (poets, novelists, playwrights etc.) have or have had an interest. ${ }^{11}$ Coughing can be an event, but it can also be an action. Wars are huge sets of both events and actions. A bomb being dropped will explode according to the laws of nature (event), but the dropping is certainly not an event; it is an action, for which somebody is accountable. A human being is both a part of and apart from nature. Natural scientists deal with events, with the being 'a-part-ofnature,' social scientists (particularly human scientists) are concerned with actions, with the being 'apart-from-nature.' The chasm between the two groups of happenings is broad and deep.

Human beings do not blindly follow a biological grammar established by laws of nature, nor are they solely shaped by unavoidable social compulsions. Man is shaping 
and being shaped by his Mitwelt and Umwelt; he is the minter being minted (see Valsiner 2014; Cohen and Kitayama 2020 and Journal of Cognition and Culture (Brill $2001 \mathrm{ff}$ ). We are able to transcend ourselves, to abstract from the concrete, to push boundaries, to look beyond our nose. As the Japanese philosopher Tetsurō Watsuji (1889-1960) put it: 'The characteristic of man is his openness (aidagara).' Man is both matter (object) and mind (subject). He has a body (Körper), but he is a body (Leib) (see Marcel 1935). In the words of Blaise Pascal (1623-1662): 'L'homme est un roseau pensant.' Man is not a thing, but a thinking thing. ${ }^{12}$

The human mind is unfathomable. It cannot be counted, weighed or computed. Culture, a reality the nature of which is mysterious, is its manifestation. ${ }^{13}$ The human mind is the world inside (Innenwelt), not the world outside (Aussenwelt); it is omnipresent, but cannot be objectified. Einstein's famous formula ( $\mathrm{E}=\mathrm{MC}$ square) is not applicable to it. However, without matter (there can be no life and without life) there can be no mind. The supposed gulf between matter and mind is only imaginary. Natural scientists and cultural scientists should engage in a dialogue with each other. Their biggest communication problem is that they do not listen actively to each other; they only listen to reply. ${ }^{14}$

A dialogue between what C.P. Snow famously called the 'two cultures' is not only desirable; it is also possible. Natural scientists study the relationships between natural phenomena, using the seven International System of Units (SI) base units and the seven defining constants. ${ }^{15}$ Cultural scientists, on the other hand, make use of 'essentially contested concepts. ${ }^{16}$ For this, cultural scientists are often scorned by their colleagues at natural science departments. However, cultural scientists too aim at knowledge that is sensibly ordered and meaningfully arranged. They too are searching how things work and why people act the way they do. Social and human scientists also are keen to make correct observations, to be critical, to reason logically and to advance plausible theories, because they want - in the words of George Shackle - 'to have their mind at rest.' Both natural and cultural scientists classify, whereby 'data' are collected and categorized (see Parrochia and Neuville 2013: 125-145; and Wilkins and Ebach 2014). Translating (mapping one idiom into another) is at least as difficult as solving an algebraic problem. ${ }^{17}$ At close scrutiny, the so-called hard sciences are softer than their practitioners are willing to admit. For example, mathematicians juggle with relations that can be transitive, antitransitive, quasi-transitive, reflexive, irreflexive, co-reflexive, symmetric, anti-symmetric, asymmetric, inverse or converse, without being able to define the concept of relation or to establish whether relations exist outside, or independent of, the human mind. A point is we learn at school - what has a place but no extensiveness. How the heck, then, is it possible that a line, being defined by Euclid as 'length without breadth,' has an infinite number of points? Things that have no extensiveness cannot be added up to something measurable, right? Besides, at enough distance, a thing of enormous size (extensiveness) may appear to be a point. If I understand Goethe well, poetry is truth shrouded in beauty. Natural and cultural scientists have much to learn from each other.

The advantage of interdisciplinary over multidisciplinary (country) research can be demonstrated by a triangle. Imagine the equilateral triangle $\mathrm{ABC}$, with the length of each edge being 1 kilometer. $\mathrm{C}$ can be reached by first going from, say, A to B, and then from $\mathrm{B}$ to $\mathrm{C}$. The total distance walked is then $1+1=2$ kilometer (the distance from $\mathrm{B}$ to $\mathrm{C}$ is added to the distance from $\mathrm{A}$ to $\mathrm{B}$ ). However, there is a considerably shorter way: going from A to $\mathrm{C}$. At each point on line $\mathrm{AC}$, both a part of the way (line) $\mathrm{AB}$ and a part of the way (line) $\mathrm{BC}$ has been covered, which - nota bene - is not a mat- 
ter of addition. Arriving at $\mathrm{C}$, the distance walked is only 1 kilometer. Generally, in a triangle $\mathrm{ABC}$, any edge is shorter than the total length of the other edges. This is not a trivial remark - unless one admits that scientists working together are more capable than scientists working separately. Composition goes beyond juxtaposition.

\section{From Triangle to Tetrahedron}

By introducing 'Father Time,' we might deepen our understanding of a country. The model representing it changes from being a triangle to being a tetrahedron, ${ }^{18}$ for a country can be conceived of as a dynamic complex system. There is subtle difference between a dynamic and dynamical system. Whereas a system can be dynamic in nature, that is, change its parameters with time, a dynamical system is one where these changes can be analyzed mathematically by using differential or difference equations. In dynamical systems theory, the variables are dated. Dynamical systems modeling is thus a kind of modeling used to represent the process which a system goes through. It focuses on how the system changes over time. Whether the evolutionary or revolutionary changes of a country are amenable to mathematical analysis is a question I am not qualified to answer, ${ }^{19}$ but pattern/form and process/flux are mutually inclusive. Each organization (structure) is the temporary result of a process that runs its course. The interrelated political, economic and social order of things at a certain time is a function of the composite order of things

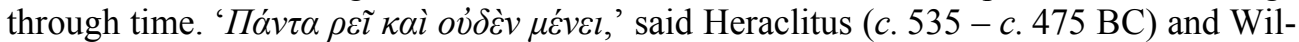
liam James, Henri Bergson and Alfred North Whitehead repeated his words in their own way. The factors involved in the change of a country can be astronomical, geological, geographic, demographic, political, legal, military, economic, financial, ecological, social, psychological, educational, medical, religious or technological in character.

Man moves while being moved; 'er schiebt und wird geschoben.' To understand this platitude, one needs not think of Planet Earth orbiting the moving sun. The past, which varies from location to location and from country to country, determines man's doings, but only partly so. Endowed with memory and fantasy, man also molds his future. The actions of kings, statesmen, religious leaders, generals, scientists, artists, inventors, explorers and entrepreneurs are prove of it that man is no robot. Man is not only passive but also active; changing in two senses (intransitive and transitive), he is not predestined. Man is not a rolling stone, the movement of which can be calculated.

By changing the triangle into a tetrahedron, we are able to assign a place to each and every science (and to its philosophy and history as well) relevant to comprehend the complexity of a country. Talking about sciences, we shall distinguish (but by no means separate) the natural from the social and human sciences. Whereas the natural, social and human sciences study phenomena in respectively the natural, social and human domain, the formal sciences are concerned with the structure of these sciences; they are aiding the non-formal sciences by providing information about the models these sciences use to describe the world. The formal sciences, which comprise mathematics, logic, statistics, computer science and systems science, are thus not concerned with the validity of theories based on observations or experimentations, but with the properties of the structures of these theories, that is to say, with the characteristics of their form (hence 'formal sciences'). Like systems science, mathematics, logic and statistics, computer science is increasingly supporting, or being applied to, non-formal sciences and - most interestingly - to the other formal sciences. This explains the dynamic nature of the formal and non-formal sciences. So it would be no exaggeration to say that the formal 
sciences are the driving force of science and technology, which in turn are the motor of economic growth.

When a country is a system consisting of three basic, interrelated elements (its territory, its people and the multifaceted organization of its people), the elements turn out to be dynamically related to each other:

- Historical sociologists can tell how societies develop through time, how social structures are shaped by complex social processes and how these structures in turn shape the institutions and organizations which affect society. ${ }^{20}$

- Historical demography is the study of human population in the past. It is not only concerned with population size and composition, but also with their changes in response to birth, migration and death. ${ }^{21}$

- We are largely children of space and time. Whereas geography (particularly human, as distinct from physical geography) may be conceived of as history in space, history (study of the human past by means of written sources) may be conceived of as geography in time. Geography and history are like conjoined twins. In the mid-1960s, inspired by the space-time model in physics, Torsten Hägerstrand (1916-2004) created time-geography. ${ }^{22}$ Paraphrasing his main message, one could say that each person's life-course is comparable to a barcode. It is unique, because the path which a person has taken in space as well as in time nobody else will be taking. What applies to a person also holds for a society or country. ${ }^{23}$ Time-geography is a kind of contextual theory, which regards the time-space setting of human activities as essential to their constitution. The crucial concept is the notion of context. $^{24}$ Temporality and spatiality are fundamental to social life. Man is not isolated. In actual fact, 'Alles ist vernetzt' and 'tout tient à tout.'

Globalization is the process of international integration, the process through which the world is becoming more interconnected and interdependent. Most contemporary social scientists endorse the view that the word globalization refers to fundamental changes in man's spatial as well as temporal experience. Geographical distance is typically measured in time. As the time necessary to connect distinct geographical locations shortens (due to technological breakthroughs), space also contracts, time-space compression being the result. The human experiences of space and time are thus closely connected. ${ }^{25}$

\section{Countries Consist of Two Types of Systems}

The discussion about the distinction and relationship between the natural and the artificial can be traced back to ancient Greece. Socrates, the first moral philosopher in the West, and Plato, his main pupil, profoundly disagreed with Sophists like Callicles and Trasymachus over the question as to whether laws were a matter of physis (given by nature) or nomos (made by man). The key question was: IS MIGHT RIGHT? The answer of the Sophists was: Yes. Socrates and Plato forcefully argued against them. ${ }^{26}$ The question is still relevant, and mostly so. Whereas Thucydides, Machiavelli, Hobbes, Nietzsche, George Kennan, Hans Morgenthau, Raymond Aron, Kenneth Waltz, Zbigniew Brzezinski, Robert Gilpin, Stephen Krasner, Paul Kennedy, John Mearsheimer, Robert Kaplan, Charles Glaser, Stephen Walt, Robert Kagan and Randall Schweller emphasized or are emphasizing the ubiquity of power and Elias Canetti (1904-1994) explores the power of the crowd in his masterpiece Masse und Macht (1960), Jeffrey Alexander advances in The Civil Society (2006), the thesis that justice, which depends on a feeling of 'being part of something larger than ourselves' (on what Adam Smith designated as fellow-feeling), is possible and civil society 'inspires hope for a democratic life.' The idea of justice became cen- 
tral to the revival of political theory unleashed by the publication of John Rawls' controversial book $A$ Theory of Justice (1972).

Countries are systems. If the political side is emphasized, countries are called 'states'; if the cultural side is stressed, they are called 'nations'. Countries have a population, a collection of individuals feeling that they have something in common, that is to say, of individuals forming a community. Since individuals are non-linearly connected, their country is a complex system, and because they interact with, and adapt to, each other, their country is a dynamic system. Finally, the complexity and dynamics of a country are reinforced by the mutual relations individuals have with their constantly changing natural environment. For example, when it starts raining (a natural event), people will, in different ways, act differently from when the sun breaks through. A tsunami, earthquake or volcanic eruption (natural events) will bring about all kinds of human actions, which differ from the actions resulting from a bombardment (certainly not a natural event).

There are different kinds of community, for example, local, national, academic, business, financial, rural, urban, political, ethnic, religious, gay, health-related, football, online, old age, or protest communities. The following sentences make this clear: 'He is well known in the local community'; 'There is a large black community living in this area'; 'Her speech caused outrage among the gay community'; 'There is a real sense of community in that neighborhood'; 'His ideas have attracted a lot of attention in the scientific community'; 'The tragedy has shocked the close-knit rural community'; 'The club is dedicated to the business community'; 'The restaurant is popular with the old age community', and 'He insulted the Chinese community as a whole'.

A community is a group of people living in an area or being considered as a unit because of their commonality. A country is a fusion of area and commonality. Countries are thus a particular kind of community. Countries are bordered stretches of land with a politically organized people who, to some extent, share a history and have a sense of belonging. Countries are locally defined and historically shaped organizations. Both locality and organization are important for characterizing a country. Think of Iceland versus Nepal, Japan versus Indonesia, Bolivia versus Afghanistan, or the United States of America (USA) versus the People's Republic of China (PRC). There are natural (grown, spontaneous or endogenous) and non-natural (constructed, man-made or exogenous) organizations or systems. The distinction between natural and non-natural organizations was highlighted by Montesquieu (1689-1755). In the course of time, there can be a change from relying on the natural to relying on a non-natural order of things. For example, whereas Christopher Columbus, Vasco da Gama, Pedro Cabral, Ferdinand Magellan and James Cook were dependent on the system of trade winds (natural order), the captain of a modern seagoing vessel relies on the chief engineer in charge of the engine room (non-natural order).

A natural order, organization, or system is an order that is not ordered by people and needs no human activity to be an order; it is an inner order, an order which is selforganized. ${ }^{27}$ For example, there are many kinds of trees, for example, beeches, oaks, elms, birches, poplars, ashes, planes, willows, lime trees, apple trees, pear trees, peach trees, plum trees, cherry trees, almonds, and walnut trees. Trees are wonderful, natural systems. Nobody is involved in their growth, which may only be facilitated by man. The roots of a tree 'know' perfectly how to suck up the nutrients-containing-water in the soil, and how much of it to suck up. The up-going sap 'knows' exactly where to change direction in order to feed the spreading branches and their leaves or ripening 
fruits. Adapting to the vagaries of the weather, trees 'know' full well when to blossom, whether to bear a certain kind and number of fruits and when to drop their leaves. Silently, trees show a recurrent pattern in space and time, without somebody ordering them to do so. Trees are indescribably beautiful, providing shelter, coolness and shade to anybody, without distinction of persons ('Ombra mai fu'). Trees dance, without somebody setting or making the rhythm. Only when they crash onto the ground and die, at man's brutal hand, they make a sound.

Whereas natural systems like the Solar system and Planet Earth can perfectly do without man, man, or the varied systems of his making, cannot do without nature. Ebb and flow will obey the laws of nature, irrespective of the rules of man. The alternation of day and night disregards any order of man. Sooner or later, death follows on birth. The seasons succeed each other non-stop. No man can change the order of nature or the course of things. What he can and often does change, however, is the result of man's organizing activities. Politicians change the ruling of a country; religious leaders steer the herd of believers in a certain direction; and businessmen induce the flock of consumers to buy their products. Politicians, religious leader and businessmen are (re)organizing something that can be changed; they issue orders, which can be either obeyed or disobeyed. The Protestant Reformation challenged the authority of the Pope; the French Revolution changed France from a monarchy to a republic; and the liberal world order is a human construct, not something natural.

Artificial, man-made organizations are arrangements which are exogenously made. They differ fundamentally from natural, spontaneous and endogenously ordered or selfregulatory organizations, like snowflakes and organisms. For example, economic inequality is a human construct; it is enduring and tenacious, but certainly not ordained from Heaven. Though Karl Marx, Max Weber, Douglass North, John Rawls, Immanuel Wallerstein, Amartya Sen, Robert Nozick, Anthony Giddens, Joseph Stiglitz, François Bourguignon, Angus Deaton, Jeffrey Alexander, Branko Milanović and Guido Alfani had done or were doing extensive and in-depth investigations into this issue, rockstar economist Thomas Piketty needed (and obtained) more than 2,000 pages to cover the subject in his books Le Capital au XXIe siècle (2013) and Capital et idéologie (2019), the much-publicized publication of which he is following up with international trips (not paid by himself) to promote their sale. Another example is the business organization. Being part of a division of a country's economy, a company is man-made; it is an artifact. An external factor is needed, namely the organizer, who not only directs and controls the organization but also divides and coordinates the labor to be performed. While the Moon orbits the Earth and the Earth orbits the Sun aimlessly (or so it seems), the leader or manager of an organization has, indeed must have a purpose. He steers the organization in a particular direction, just like the cyclist on his bike, the driver of a car, the captain in charge of a ship or the pilot controlling an aircraft. Study of the leadership of a company is a form of applied cybernetics. When the organization under his leadership grows, the leader will employ assistants or delegate some of his responsibilities. His core task, however, will remain the same: making strategic decisions. These decisions involve employment and investment decisions, which means that he should be informed of the situation at, and developments in, the labor market and money or capital market respectively. Exploiting the potential of these markets, he continuously tries, possibly by means of his research and development department, to improve the quality of his company's products, and he looks, by means of his sales and marketing division, 
for opportunities to sell his products on the local, national or international market. With the R\&D division, the sales and marketing department and other parts of the organization nicely in place (set up according to his directives), the leader shows that he knows how to divide, coordinate and control the jobs or tasks to be carried out, that is, how to establish effective relationships between employees, means, tools and activities in order to achieve an objective, the relationships being defined quantitatively, qualitatively, spatially, temporally or in terms of power.

Countries are certainly not companies, but countries and companies are largely human constructs. Leadership (the directing of people) is their essence. Another word for leadership is 'management', which implies organization of the company, division of the tasks to be performed and control of activities carried out. When it comes to performing tasks or controlling activities, ruling a country may show a considerable degree of latitude; it implies organization and government (management) nonetheless. This indicates that study of the leadership of both a company and a country is essentially a form of applied cybernetics. The word cybernetics comes from $к \nu \beta \varepsilon \rho v \eta \tau \imath \kappa \eta$, that is, from all that is pertinent to $\kappa v \beta \varepsilon \rho v \alpha \dot{\alpha} \omega$ (to steer, to navigate), hence the $\kappa \nu \beta \varepsilon \rho v \eta \dot{\tau} \tau \varsigma$ is the helmsman, the manager or the governor.

Perhaps the best way to see the discrepancy between natural and man-made order is to realize the fundamental difference between actions and events. Whereas events are caused, actions have reasons, that is to say, the human mind is involved in actions. Causes may be difficult to identify and determine, because the chain of causes is often long and their interdependence is hard to ascertain. Even more difficult is it to gauge the human mind and to fathom out what humans are moved by.

\section{A Country is a Complex and Dynamic System}

Countries are complex and dynamic systems consisting of complex and dynamic subsystems; they have related (!) levels of systems. But what is a system and what is the difference between systems and sets?

Set theory, the brainchild of Georg Cantor (1845-1918), was born from the collecting of things, which led to the concept of number, the subject of number theory (according to Gauss, the 'queen of mathematics'). Set theory changed the entire outlook on measure and integration; it relates to group theory, because a mathematical group is a non-empty set of elements, which can be combined in a particular way and under certain conditions. The language of Cantor's theory is used for defining nearly all mathematical objects, but most of his theory dealt with 'Punktmengen' (sets of points). Cantor defined a set as 'any collection of distinguished objects gathered into a whole'.

Before collecting things, they have to be identified, but the concept of identity is far from clear. The word identical, or synonyms thereof, appears in sentences like ' $\mathrm{x}$ is identical with $y$ ', ' $x$ is the same as $y$ ' and ' $x$ is equal to $y$ ', or, for the sake of brevity, $x=y$. Instead of ' $x$ is not identical with $y$ ', or ' $x$ differs from $y$ ', we write $x \neq y$. Strictly speaking, however, there is no identity, and when there is no identity, it makes no sense to speak of difference, because 'identity' and 'difference' are correlative (mutually involving) concepts. If a drop of water falls into the sea, there is no identity, for the volume of the sea changes.

In everyday language, identity is usually expressed by the use of 'is', or by another form of the verb 'to be' ('am', 'are', 'was', 'were', 'being', or 'been'). For example: 'Rome is the capital of Italy,' 'Shakespeare is the author of Hamlet,' or 'Oxygen is the 
chemical element with the symbol O.' The 'is' in these sentences differs, however, from the 'is' in phrases like 'Rome is a city,' 'Shakespeare is/was a playwright' or 'Oxygen is a nonmetal.' In the first three sentences, reversal is possible: 'The capital of Italy is Rome,' 'The author of Hamlet is Shakespeare' and 'The chemical element with the symbol O is oxygen.' Reversal is impossible in the last three phrases, because 'is a city,' 'is/was a playwright' and 'is a nonmetal' are predicates, giving information about respectively the subject Rome, Shakespeare and oxygen. We leave here the machinery of propositional logic and enter the vast domain of first-order and higher-order logic, the discussion of which falls beyond the scope of this article. ${ }^{28}$

Once collected, things form a collection, a set. For example, the collection consisting of a book, a digital camera, a deck of cards, an guitar and a pencil, the set formed by the boys who are absent from the school in town $\mathrm{x}$, or the assortment of vegetables in a supermarket. Classes of individuals are first-order classes. Second-order classes do not consist of individuals but of first-order classes. There are also third-order, fourth-order, etc. collections. The study of classes (their nature, notation, operations on, and relations between, them) is called set theory.

A system is a particular set. Whereas a set is a collection of things, a system is a collection of connected things. Their interconnectedness is to be emphasized, because interconnected things form a unit having properties, a boundary and an environment. The difference between set and system is a subtle but important one. A set is just a collection of objects having something in common. For example, the men of a town form a set; what they have in common is only their being resident of the town. They are not connected. All the persons (men, women and children) of a town, however, form a system, because, living in or belonging to the town, they form a community which differs from other communities. Tensions between residents do not distract from their being connected. The products for sale in a department store form a set, but the interconnected parts of a bicycle, car, train, plane, or computer form a system. If the connected things belong to the physical world, it is a physical system; if they belong to the living world, it is a living or biological system, and if they belong to the human society, it is a social system. The immune system (not: set) interacts with both the nervous and the hormone system, or, to take a few examples from the social domain, a company, political party and religious community are more than sets; they are systems, operate as units, and interact or communicate with their environment. External communication is often more difficult than internal communication, though the difficulties attendant on intra-group communication should not be underestimated. Further distinctions can be made. For example, social systems are divided into political, legal, military, economic, financial, management, linguistic, literary, cognitive, religious, cultural and technological systems. A worldview is not a collection of unrelated beliefs. It is a cognitive system, a collection of interconnected beliefs. Its most fundamental concept may be ill-conceived, but it is a system all the same. System differentiation has often led to losing sight of the nature and essence of a system tout court. The study of systems is called systems science and should thus be clearly distinguished from set theory.

A system is composed of a number of interrelated parts. Two aspects are involved: (a) the parts forming, composing or making up the system, and (b) the way in which these parts are related to each other. Discoveries made since 1970 have shown that these relations are usually non-linear (see Scott 2007: 79-100). The non-linearity of the relations between the parts of a system makes it a complex system. To a degree, systems are 
separated from their surroundings by a boundary. Each system is, therefore, conditioned and constrained. There is nothing totally isolated, however. A sub-system is both a collection of connected elements (its components or constituents) and a component of a larger system (the sub-system's super-system). Complete description of a system contains also information about its environment; the description of a system that does not contain information about its environment is thus incomplete and potentially misleading. No political, economic or social system operates in a vacuum. An overall system is a nested system; it is rather difficult but not impossible to describe. The change of one part of a system induces the change of another part and of the system as a whole.

Over time, a series of changes forms a process that has a structure or pattern to be identified and explained. The system is not only complex; it is also dynamic. Identifying and explaining the process pattern (Wandlungsstruktur) of a country's history that consists of many interconnected and changing sub-systems having numerous interrelated and transforming constituents is the daunting task of historians - a task, I venture to claim, they are not scientifically equipped to carry out. There is much work still to be done. For example, the complexity and dynamics of the agricultural, industrial and service sector of an economy, which is only one, albeit very important aspect of a country, have been extensively researched and well documented, but the super-context (the context of the context of the economic sectors) is not yet thoroughly investigated, because the investigators (clinging on to ceteris paribus clauses) are blinkered. Historians who refuse to collaborate with, say, economists, political scientists, demographers, geographers and sociologists should apply for a job as journalist or country correspondent; universities are not the places where they belong. Adaptation of a system is the way a system adjusts to its changing environment. Systems often exist for the service of a single person (or group of people serving this man/woman) having personal (or group/party) interests that may run counter to what is natural. The management of a system may therefore result in its failure or breakdown. When management increases in complexity (e.g., when ruling a modern nation-state), the risk of system failure or breakdown will increase. History is littered with them.

Systems can be either closed or open. A closed system does not allow transfers into or out of it. The specification of what types of transfers are excluded varies in the closed systems of physics, chemistry or engineering. For example, a system might be closed to energy, meaning that energy is neither able to enter nor to leave it. A vacuum thermos flask stops energy from leaving the system to keep the drink it contains warm. So it might make sense to treat the flask as a closed system. However, no system in the real world is perfectly closed. An open system has external interactions, which may take the form of energy -, information - or material transfers into or out of it, depending on the discipline defining the system. If one pours hot drink into a mug, the heat will relatively quickly escape to its surroundings. Open systems are more difficult to understand than closed systems. This may be the reason why scientists tend to prefer working with systems they mistakenly presume to be closed. In the social sciences, an open system exchanges material, energy, information (data), people and capital with its environment. Kostas Axelos (1924-2010), a Greek-French philosopher, cogently argued that seeing the world system (and any part/country of it, I would like to add) as an inherently open system would solve many problems. ${ }^{29}$ Social and human scientists would, therefore, be better advised not only to stay in touch with natural scientists, but also to work closely together, rather than creating a monopoly whereby the world (or a country) is looked at 
through, for example, political, legal, military, economic, financial, demographic, geographic, sociological, psychological, linguistic, literary, or cultural spectacles. ${ }^{30}$

\section{Comprehending a Country}

When a country is a complex and dynamic system, the question arises as to how to study the country and how to comprehend such a system. After years of pondering over this matter, it dawned on me that I had to consult experts in the science of complex systems. For clearly, any (would-be) political scientist, economist, demographer, sociologist or anthropologist lecturing on the country as a whole has to be distrusted. No ant can perceive the pattern of the whole carpet. 'To comprehend' stems from the Latin word 'comprehendere' (to take together, to unite). Comprehending a country means understanding it not partly but completely, that is to say, taking all the possible viewpoints into account. This can only be achieved by a team of seasoned scientists, by truly collaborating bright minds from different countries, particularly from the country being researched in order to ensure that the theories advanced are tested or at least testable. Multidisciplinary work - it cannot be overstressed - will not do, for a cathedral is far more than the sheer piling or juxtaposing of stones, things that can be counted.

Comprehending the dynamic complexity of a country is the challenge no serious scientist of complex systems can afford not to take on. It is par excellence the challenge of interdisciplinary researchers. ${ }^{31}$

\section{Is It Possible to Comprehend a Country?}

I think it is technically feasible to advance the comprehension of a country's complexity, provided the growing power of computers is harnessed. Computer science could stimulate systems science, and vice versa. Systems science is pre-eminently suitable to map the complex and dynamic systems which a country is composed of and to chart the relationships prevailing among them. When both computer science and systems science are further developing, the possibility of interaction between them should be explored. Instead of heavily leaning on either the computer science or systems science side, a more balanced approach would take advantage of the strength at both sides. An international conference on this issue is needed.

The question may be raised how to digest the huge chunk of information collected in a conventional country library. If systems and computer science could be helpful in comprehending a country, I think there is reason to be cautiously optimistic about the applicability of computer science to such studies. As the potential of digitized libraries is growing fast, they may help to cope with the complexity of a country in a way undreamed of by scholars in the past and their current colleagues.

A digital library is a collection of digital objects stored electronically along with means for organizing, managing and retrieving the information or knowledge contained in, or related to, the objects. Digital libraries, the concern of Library and Information Science (LIS) ${ }^{32}$ vary in scope, can be maintained by individuals or organizations, can be affiliated with physical libraries or academic institutions, and can be integrated, which is essentially a case of knowledge integration. The content of digital libraries may be accessed remotely or via a network of computers.

The humanities are currently undergoing a revolution similar to what happened in the life sciences twenty years ago with the collection and centralization of genomic data. The marriage between computer science and humanities has resulted in the thriving field of 
digital humanities. Very large databases, new computational approaches and digital collaborative technologies are reshaping the humanities, opening up promising avenues for research and education in country studies. The discipline of digital humanities explores the potential of these new methods and the scholarly practices fostered by digital technologies.

Myriads of books and scholarly journals are stacked in libraries throughout the world. Some of these libraries are digitized and their number is rapidly growing. The advantages are obvious:

- The fast growing potential of 'human-computer interaction' (HCI) can be deployed. ${ }^{33}$

- Digitized libraries can be quickly, remotely, simultaneously and systematically searched.

- Double/multiple counting can be avoided.

- Books and journals (articles) on a particular country can be selected.

- Books and journals (articles) on a particular country can be arranged by year/month of publication.

- Books and journals (articles) on a particular country can be arranged by publisher.

- Entries can be alphabetized.

- Entries can be systematically cataloged by (sub) discipline or topic.

- Entries can be listed in order of some kind of frequency.

- Entries can be listed by the time a subject is first addressed, or further advanced.

- Indexes (alphabetical lists of names or subjects, with their location) can be drawn up and integrated.

- Concordances (alphabetical lists of the words used in a book or article, with their immediate context) can be compiled and integrated.

- Contents mentioned in tables of contents can be systematically arranged and synoptically outlined.

- Digitalization facilitates analysis and cross-checking.

- Semantic fields can be explored.

- Schemes of concepts or keywords can be mapped and visualized.

- Technical terms and expressions can be clarified by relating and organizing them.

- The tools, techniques and methods of text analysis (aka text mining) and topic modeling can be used. With text analysis, computational linguistics and computer-aided translation sufficiently developed, it may even be possible to discover and sort out re- or paraphrasing.

- The tools, techniques and methods of information and knowledge integration can be used.

- The tools, techniques and methods of information fusion can be used.

- The tools, techniques and methods of natural language processing (NLP) can be used. The Natural Language Processing Group at Stanford University may be appealed to.

- Quantitative data can be collected and subjected to statistical analysis. This kind of analysis is particular important, as the volume of available quantitative data is growing and the statistical apparatus is becoming increasingly sophisticated. Quantitative linguistics is booming. Go to http://www.iqla.org.

- The desirability and feasibility of performing a meta-analysis can be explored. A meta-analysis combines the results of multiple scientific studies.

- National data on authors, contributors or translators can be sifted and orderly mapped. 
- Personal data on authors, contributors or translators can be sifted and orderly mapped (education, appointment[s], institution[s] associated with, prize[s], award[s], publication[s] etc.).

- A master bibliography can be alphabetically or thematically compiled, kept up-todate and explored.

- IT-connections can be established with publishers of books or journals on a country.

- IT-connections can be made with databases which are partly or wholly related to a country.

The last two points will enable the aspirant author to acquaint him/herself with, or stay abreast of, recent information on the subject he/she is interested in or wants to write about.

Computer-supported collaborative learning about, computer-supported cooperative work on and interdisciplinary as well as international research into a country can be facilitated by the use of digital libraries. The collaboration between country-focused scientists from different countries and different disciplines can be stimulated, and the coherence and integration of their work can be enhanced. By computationally collating data from diverse sources a well-planned project geared to international and interdisciplinary country-research will come to fruition and novel insights into how a country functions and develops will be provided. The wiring of the country will be discovered and its overall pattern or deep structure will show up.

Computationally visualized relationships and interdependences may suggest further research. The importance of computationally creating an image of both the weft and the warp of a country's carpet is to be emphasized, because many scholars, bewildered about the intimate relationship between the spatial (simultaneous) and the temporal (consecutive), are unfamiliar with, or inclined to underrate, the possibilities of information visualization.

Multi-volume dictionaries and thesauri can be systematically searched in a minute, a modern atlas can display detailed information about a geographical area's different aspects, and the streets and side streets of any city can be almost instantly mapped and visualized, but the potential of digitized and electronically connected libraries and archives is at present heavily underestimated.

Digital libraries are huge databases, large collections of data which are electronically accessible to big data analysts using cutting-edge software that runs on state-of-the-art supercomputers. Completely new and hitherto unknown structures of, and heretofore unimagined patterns between, countries could be discovered. As integrated and interactive computer systems, such libraries could make computationally visible that any countrytopic chosen for research is only part of a complex and dynamic system, in other words, is nothing but the node of a poly-dimensional and multi-layered network. All the relevant dots can and shall be connected. The deployment of digital libraries could give an enormous boost to collaborative country research. Consequently, it could improve the understanding of countries that is needed by foreign affairs ministers and world leaders.

The electronically accessible Encyclopedia of Life Support Systems is 'one of the largest e-books repositories on the Web,' an 'integrated compendium of twenty-one encyclopedias,' and 'a virtual dynamic library of about 600 volumes.' The EOLSS body of knowledge 'attempts to forge pathways between disciplines in order to show their interdependence.' It 'deals in detail with interdisciplinary subjects, but it is also disciplinary, as each major core subject is covered in great depth by world experts.' EOLSS is testimony 
of it, that partial studies which are not nicely dovetailed or firmly interlocked with each other present nothing but a 'spectacle coupé,' a Humpty Dumpty broken into bits. The parceling up of a whole neglects relations that matter and the compartmentalization of a complex system into 'more manageable' subsystems easily results in losing sight of the context. Conducting partial studies makes thus only sense if they are conceived of as, and demonstrated to be, the constituents of a coherent whole. If the repository Encyclopedia of Life Support Systems is available online and serves the interests of many scientists, it should be possible to create a similar storehouse of information related to a country. The electronic hookup between country-related depots, which network scientists would call the nodes (or vertices) of a network, makes comparative research possible and bring the international context or foreign relations of a country to light.

In 2005, James Billington, late chief librarian of the Library of Congress, suggested to UNESCO director-general Kōichirō Matsuura that a World Digital Library (WDL) might be created which would 'have the salutary effect of bringing people together by celebrating the depth and uniqueness of different cultures in a single global undertaking.' Dr. Matsuura welcomed the proposal as a 'great initiative that will help to bridge the knowledge divide and promote mutual understanding.' The WDL was launched in April 2009 and developed by a team of the Library of Congress, with technical assistance of the Bibliotheca Alexandrina, in Alexandria. Institutions contributing to the WDL include national libraries and cultural and educational institutions in Brazil, China, Egypt, France, Iraq, Israel, Japan, Mali, Mexico, Morocco, the Netherlands, Qatar, the Russian Federation, Saudi Arabia, Serbia, Slovakia, South Africa, Sweden, Uganda, the United Kingdom and the United States. The WDL is an impressive undertaking, but the potential of digitized and electronically connected libraries and archives is still far from being fully exploited.

Mention should also be made of the list of lists (of lists) available on the Internet (https://en.wikipedia.org/wiki/List_of_lists_of_lists), particularly of the lists of countryrelated topics. The references are hyperlinked. So visiting the websites will have a snowballing effect. Needless to say, country information available on the Internet would be tremendously increased, if only book publishers were willing to loosen their open-access conditions. Unfortunately, their current business model blocks scientific progress.

All this does not mean, even in principle, that countries can be fully computationally comprehended, because the human mind (as distinct from his brain) is and will always remain incomprehensible. Sooner or later, every computer, being constructed and instructed and even having to be switched on by a human, will be outsmarted by man, the ever elusive being (see Ornes 2020). Compared to natural events (the intertwined causes of which may be difficult to trace), individual actions are particularly complex and more difficult to understand. Social actions are particularly complex and even more difficult to understand. When more than two individuals are involved, the understanding of social actions by means of the tools used in the natural sciences quickly becomes impossible. In comparison, the notorious three-body problem ${ }^{34}$ pales.

The main conclusion of this article is that current country-studies have to be rejected as being fundamentally flawed and that computer-aided interdisciplinary and international collaboration is the key to successful research on countries, being the dynamic and extraordinary complex parts of a worldwide whole. 


\section{NOTES}

1 'Order' comes from the Vedic word 'Rta' and is related to 'right'; it refers to the harmonious adaptation of the parts to the whole they constitute. See Émile Benveniste (1969: 99-105).

${ }^{2}$ The band (or horde), the tribe, and the chiefdom are hierarchically ordered preliminaries to the state.

${ }^{3}$ For example, see the Cambridge Companions to Culture. Almost every country-related book begins perfunctorily with a chapter on the land and its people, without caring to integrate it tightly with the remaining chapters.

${ }^{4}$ See Richardson et al. 2017. For physical geography, a subfield of the geoscience, see Petersen et al. 2017. For human geography, see Kobayashi 2019. Visit https://igu-online.org.

${ }^{5}$ Amos Rapoport, one of the founders of Environment-Behavior Studies, deals authoritatively with this subject in Companion Encyclopedia of Anthropology (Rapoport 2002: 460-502).

${ }^{6}$ Probably nobody has written more elaborately about this subject than the Chinese-American geographer Yi-Fu Tuan, who bases himself on the great book of Gaston Bachelard (1884-1962), La Poétique de l'espace (1957). Human geographers, no matter their specializations, are concerned with the spatial differentiation and organization of human activity and with human use of the physical environment.

${ }^{7}$ See Caselli et al. (2001-2006) and consult the Springer series on Demographic Methods and Population Analysis (1988ff). Also explore https://population-europe.eu and https://population.un. org/wpp.

${ }^{8}$ For organization studies, which have much in common with systems science, see Clegg and Bailey 2008.

${ }^{9}$ A list of areas (subfields) of law can be found on the Internet.

${ }^{10}$ I found Reus-Smit and Snidal (2010) and Sauer and Masala (2017) wanting in stressing and underlining the importance of the interrelationship between foreign and domestic affairs.

${ }^{11}$ Human actions have been the subject of extensive research. See Blondel (1893), von Mises (1949), Kotarbiński (1965), Oakeshott (1975), Habermas (1981) and Gasparski (2018). Pragmatism is a philosophy related to action. Visit http://actiontheory.free.fr, https://philpapers.org/s/action, https://plato.stanford.edu/entries/action and https://plato.stanford.edu/entries/behaviorism.

${ }^{12}$ The famous dictum of René Descartes, 'Cogito ergo sum' is a fallacy, because it begs the question: the argument's premise ('je pense') assumes the truth of the conclusion. Descartes is said to have laid the foundation for the Enlightenment and to be one of the founders of modern philosophy. Giambattista Vico (1668-1744), who has only recently received the attention he deserves, disagreed with him.

${ }^{13}$ This seems to contradict what Kevin Laland argues in Darwin's Unfinished Symphony: How Culture made the Human Mind (2017), but mind and culture are mutually conducive and reciprocally reinforcing.

${ }^{14}$ In a dialogue, partners really listen to each other, attempting to find the truth. In a debate, they only try to defeat each other and want to be victorious.

${ }^{15}$ Go to www.bipm.org.

16 See Margolis and Laurence 1999. For more literature and related subjects, visit https://plato.stanford.edu/entries/concepts.

${ }^{17}$ See Frühauf (2017) and browse the journals Approaches to Translation Studies (1975ff), Target (1989ff), Translation and Interpreting Studies (2006ff), Translation Studies (2008ff) and Translation Spaces (2012ff).

${ }^{18}$ Historically and mathematically, the tetrahedron is an interesting object. A scientific model is not a jumble of ideas, but a simplifying representation of a piece of actual or imagined reality. It can be empirical, theoretical, static, dynamic, discrete, continuous, descriptive, prescriptive, explicative, predictive, deterministic or stochastic. Visit https:/www.iep.utm.edu/models and https://plato.stan ford.edu/entries/models-science.

${ }^{19}$ See the Handbook of Dynamical Systems (Elsevier, 2002ff). Visit https://plato.stanford.edu/ entries/evolution and https://plato.stanford.edu/entries/revolution. See also Goldstone 2014. 
${ }^{20}$ Browse the Journal of Historical Sociology (1988ff) and Cultural Dynamics (1988ff). The study of the structure and change in economic history, particularly research on the history of capitalism, tacitly and unwarrantedly presupposes an interdisciplinary and international investigation of the structure and (evolutionary or revolutionary) change in history in general. In his monumental twovolume study Law and Revolution, Harold Berman, building on the groundbreaking work of Eugene Rosenstock-Huessy (go to https://plato.stanford.edu/entries/rosenstock-huessy), describes in meticulous detail the formation of the Western legal tradition, without taking non-Western legal traditions into full account. Über den Prozeß der Zivilisation, the masterpiece of Norbert Elias (1897-1990), is regarded as a work foundational to figurational sociology (aka process sociology), but the book is exclusively concerned with European countries. Elias, Rosenstock-Huessy and Berman can thus be accused of parochialism. For Uwe Wesel's review of Berman's book (vol. I), see Die Zeit, August, 1991, p. 46. World Development (1973ff) is 'the multi-disciplinary international journal devoted to the study and promotion of world development,' but leaves the reader in the dark about the complex interconnectedness of all the disciplines concerned with development.

${ }^{21}$ Visit the website of the International Commission for Historical Demography.

${ }^{22}$ His swansong and masterpiece about the fabric of human existence has not yet been translated into English.

${ }^{23}$ Browse the Journal of Historical Geography (1975ff).

${ }^{24}$ See Simonsen 1991: 417-431. Much has been written about context. Suffice it to mention Jonathan Ichikawa's Handbook of Epistemic Contextualism (Ichikawa 2017).

${ }^{25}$ Visit https://plato.stanford.edu/entries/globalization and https://ycsg.yale.edu. Karl Schlögel, Im Raume lesen wir die Zeit (2003) was an eye-opener. For the view of physicists on space and time, go to http://www.spacetimesociety.org and http://www.qiss.fr/consortium.html.

${ }^{26}$ The books to be read are William Conklin, The Invisible Origins of Legal Positivism (2001: Introduction), Pierris Apostolos, Physis and Nomos (2007), Marc Garcet and Serge Dalla Piazza, Entre Physis et Nomos (2016) and Thanos Zartaloudis, The Birth of Nomos (2020; publication of the companion volume The Birth of Physis is forthcoming).

${ }^{27}$ See Camazine et al. (2003), Bertelle et al. (2008) and Dedié (2015). Go to http://www.scholar pedia.org/article/Self-organization, https://plato.stanford.edu/entries/properties-emergent, https://iep.utm. edu/emergenc and https://www.d-iep.org/diep.

${ }^{28}$ See Russell and Norvig (2010: 285-321) and go to https://plato.stanford.edu/entries/logichigher-order.

${ }^{29}$ See Kostas Axelos, Systématique ouverte (1984). For an interview with Axelos, see Radical Philosophy 130:1 (March/April 2005): 25-28.

${ }^{30}$ The literature on systems science is overwhelming. To begin with, the reader could turn to Günter Ropohl, Allgemeine Systemtheorie: Einführung in transdisziplinäres Denken (2012), Albert Rutherford, The Elements of Thinking in Systems (2019) or Ray Ison and Ed Straw, The Hidden Power of Systems Thinking (2020). For complex systems theory, the reader is advised to consult the Springer series Understanding Complex Systems (2004ff) and Proceedings in Complexity (2013ff), but a visit to http://www.art-sciencefactory.com/complexity-map_feb09.html and https://www.santafe.edu is indispensable.

${ }^{31}$ The literature about interdisciplinary research, a subject closely related to the ongoing search for the unity of science, is large and growing rapidly. The reader should begin with Julie Thompson Klein, Interdisciplining Digital Humanitiess (2015) and Allen Repko and Rick Szostak, Interdisciplinary Research: Process and Theory (2020). The websites to be explored are https://interdisciplinarystudies. org, http://ciret-transdisciplinarity.org, https://www.bu.edu/cgs/citl, http://intrepid-cost.ics.ulisboa.pt, https://www.shapeid.eu, https://inidtd.org, https://www.isko.org and https://www.eolss.net. It would be fascinating to study the applicability of the science of systems to the system of sciences, making use of the insights of mereology (the study of parthood)!

${ }^{32}$ LIS is the merger of library science and information science. See Rubin R. and Rubin R. (2020). The interdisciplinary and international high-impact journal The Internet and Higher Education (1998ff) is a must-read. 
33 For human-computer interaction, see the Springer Human-Computer Interaction Series (2004ff). Also go to www.hci.international, http://tochi.acm.org, https://hcipioneers.wordpress.com and http://hcibib.org.

${ }^{34}$ Go to http://www.scholarpedia.org/article/Three_body_problem.

\section{REFERENCES}

Alexander, J. 2006. The Civil Society. Oxford University Press.

Apostolos, P. (ed.) 2007. Physis and Nomos. Patras: Institute for Philosophical Research.

Aronson, E. et al. 2019. Social Psychology. New York: Pearson.

Axelos, K. 1984. Systématique ouverte. Paris: Éditions de Minuit.

Bachelard, G. 1957. La Poétique de l'espace. Paris: Les Presses universitaires de France.

Benveniste, É. 1969. Le vocabulaire des institutions indo-européennes, II. Paris: Les Éditions de Minuit.

Bertelle, C. et al. (eds.) 2008. Complex Systems and Self-Organization Modelling. Springer.

Blondel, M. 1893. L'action. Paris: Alcan.

Camazine, S. et al. 2003. Self-Organization in Biological Systems. Princeton: PUP.

Canetti, E. 1960. Masse und Macht. Hamburg: Claassen.

Caselli, G. et al. 2001-2006. Démographie: Analyse et Synthèse. Paris: INED.

Clegg, S., and Bailey, J. (eds.) 2008. International Encyclopedia of Organization Studies. Thousand Oaks, CA: Sage.

Cohen, D., and Kitayama, Sh. (eds.) 2020. Handbook of Cultural Psychology. Guilford.

Conklin, W. 2001. The Invisible Origins of Legal Positivism. Springer.

Dedié, G. 2015. Die Kraft der Naturgesetze. Hamburg: Tredition.

Delamater, J. et al. 2015. Social Psychology. New York: Westview Press.

Frühauf, M. 2017. Tour d'horizon über translatorische Theorien und Beobachtungen aus der Praxis des Übersetzens. Bochumer Jahrbuch zur Ostasienforschung 40: 5-32.

Garcet, M., and Dalla Piazza, S. 2016. Entre Physis et Nomos. Paris: L'Harmattan.

Gasparski, W. 2018. Praxiological Essays. New York: Routledge.

Georgescu-Roegen, N. 1971. The Entropy Law and the Economic Process. Harvard University Press.

Goldstone, J. 2014. Revolutions: A Very Short Introduction. Oxford; New York: Oxford University Press.

Gyftopoulos, E., and Beretta, G. 2012. Thermodynamics: Foundations and Applications. Dover.

Habermas, J. 1981. Theorie des kommunikativen Handelns. Suhrkamp.

Ichikawa, J. (ed.) 2017. Handbook of Epistemic Contextualism. London: Routledge.

Ison, R., and Straw, E. 2020. The Hidden Power of Systems Thinking. London: Routledge.

Kobayashi, A. (ed.) 2019. International Encyclopedia of Human Geography. Elsevier.

Kotarbiński, T. 1965. Praxiology: An Introduction to efficient Action. Pergamon.

Laland, K. 2017. Darwin's Unfinished Symphony: How Culture made the Human Mind. Princeton: Princeton University Press.

Marcel, G. 1935. Etre et avoir. Aubier.

Margolis, E., and Laurence, S. (eds.) 1999. Concepts: Core Readings. MIT Press. 
Oakeshott, M. 1975. On Human Conduct. OUP.

Ornes, S. 2020. How Close Are Computers to Automating Mathematical Reasoning? Quanta Magazine, August 27.

Parrochia, D., and Neuville, P. 2013. Towards a General Theory of Classifications. Birkhäuser.

Petersen, J. et al. 2017. Physical Geography. Cengage.

Piketty, Th. 2013. Le Capital au XXIe siècle. Paris: Seuil.

Piketty, Th. 2019. Capital et idéologie. Paris: Seuil.

Rapoport, A. 2002. Spatial Organization and the Built Environment. In Ingold, T. (ed.), Companion Encyclopedia of Anthropology? (pp. 460-502) London: Routledge.

Rawls, J. 1972. A Theory of Justice. Oxford university Press.

Repko, A., and Szostak, R. 2020. Interdisciplinary Research: Process and Theory. Sage.

Reus-Smit, Ch., and Snidal, D. (eds.) 2010. The Oxford Handbook of International Relations. Oxford: Oxford University Press.

Richardson, D. et al. (eds.) 2017. International Encyclopedia of Geography. Wiley.

Ropohl, G. 2012. Allgemeine Systemtheorie: Einführung in transdisziplinäres Denken. Sigma.

Rubin, R., and Rubin, R. 2020. Foundations of Library and Information Science. ALA Neal-Schuman.

Russell, S., and Norvig, P. 2010. Artificial Intelligence: A Modern Approach. Pearson.

Rutherford, A. 2019. The Elements of Thinking in Systems. Independently published.

Sauer, F., and Masala, C. (eds.) 2017. Handbuch Internationale Beziehungen. Wiesbaden: Springer VS.

Schlögel, K. 2003. Im Raume lesen wir die Zeit. Hanser.

Scott, A. 2007. The Nonlinear Universe. Springer.

Simonsen, K. 1991. Towards an Understanding of the Contextuality of Social Life. Environment and Planning D: Society and Space 9: 417-431.

Smelser, N., and Baltes, P. (eds.) 2015. International Encyclopedia of the Social \& Behavioral Sciences. Elsevier.

Smil, V. 2017. Energy and Civilization: A History. MIT Press.

Thompson Klein, J. 2015. Interdisciplining Digital Humanitiess. University of Michigan Press.

Turns, S. 2006. Thermodynamics: Concepts and Applications. CUP.

Valsiner, J. 2014. An Invitation to Cultural Psychology. Sage.

van Lange, P. et al. (eds.) 2012. Handbook of Theories of Social Psychology. Sage.

von Mises, L. 1949. Human Action. Yale University Press.

Wilkins, J., and Ebach, M. 2014. The Nature of Classification. Palgrave MacMillan.

Zartaloudis, Th. 2020. The Birth of Nomos. Edinburgh University Press. 